\title{
Hubungan Disiplin Kerja Terhadap Kinerja Karyawan Pada PT. Mensa Bina Sukses Makassar
}

\author{
Fakhruddin Kurnia $\mathbf{M}^{* 1}$ \\ Trian Fisman Adisaputra ${ }^{2}$ \\ 1,2Manajemen, Sekolah Tinggi Ilmu Ekonomi Ichsan Sidenreng Rappang, Indonesia \\ *e-mail: fahruddinkurnia20@gmail.com ${ }^{1},{\underline{\operatorname{trian} 260691 @ g_{\text {gmail.com }}^{2}}}^{2}$
}

(Naskah masuk : 6 Mei 2021, Revisi : 15 Mei 2021, Publikasi : 25 Mei 2021)

\begin{abstract}
Abstrak
Penelitian ini bertujuan mengetahui tingkat kedisiplinan kerja terhadap peningkatan kinerja pegawai oleh pihak PT. Mensa Bina Sukses Makassar. Metode analisis perhitungan data dilakukan dengan menggunakan metode deskriptif dimana untuk mencari tingkat kedisiplinan karyawan terhadap peningkatan kinerja karyawan serta keterkaitan atau hubungan antara kedisiplinan karyawan terhadap peningkatan kinerja karyawan, serta menggunakan perhitungan analisis kualitatif untuk mencari pengaruh kedisiplinan karyawan terhadap kinerja karyawan. Hasil dari penelitian ini adalah dari hasil menggunakan metode analisis kualitatif didapatkan dari nilai pengaruh yang tinggi sebesar $Y=8,55+0,83 X$, dimana ada pengaruh antara kedisiplinan dan kinerja karyawan. Dan sebagai masukan bagi perusahaan untuk lebih menegaskan kepada karyawannya dimana kesadaran disiplin kerja sangat berpengaruh terhadap peningkatan kinerja karyawan.
\end{abstract}

Kata kunci: Disiplin, Kinerja, Karyawan.

\begin{abstract}
This study aims to determine the level of work discipline towards improving employee performance by the PT. Mensa Bina Sukses Makassar. The method of data calculation analysis is carried out using descriptive methods in which to find the level of employee discipline towards employee performance improvement and the relationship or relationship between employee discipline and employee performance improvement, as well as using qualitative analysis calculations to find the effect of employee discipline on employee performance. The results of this study are the results of using qualitative analysis methods obtained from a high influence value of $Y=8.55+0.83 \mathrm{X}$, where there is an influence between discipline and employee performance. And as input for the company to emphasize more to its employees where awareness of work discipline is very influential on improving employee performance.
\end{abstract}

Keywords: Discipline, Employees, Performance.

\section{PENDAHULUAN}

Dalam rangka usaha untuk mencapai tujuan suatu organisasi, diperlukan adanya para Sumber Daya Manusia yang memiliki displin yang baik sebagai unsur penting dalam suatu organisasi. Kedisiplinan itu sangat penting dalam peningkatan kinerja seseorang, sebab dengan disiplin maka semua tugas akan dapat selesai dengan baik dan tepat waktu. Sumber Daya Manusia memegang peranan penting dalam suatu perusahaan, tanpa bantuan dan peran para Sumber Daya Manusia, program kerja yang telah ditetapkan tidak dapat terlaksana secara efektif dan efisien. Oleh karena itu perlu kerja sama yang terkoordinasi dalam upaya mencapai tujuan yang telah ditetapkan sebelumnya agar dapat benar-benar terlaksana. Tujuan perusahaan dapat dicapai apabila manejemen mampu mengelolah, menggerakkan, dan menggunakan Sumber Daya Manusia (SDM) yang dimilikinya secara efektif dan efisien. Sumber Daya Manusia (SDM) adalah faktor penting dalam setiap perusahaan baik perusahaan milik pemerintah maupun swasta.

Kedisiplinan adalah kesadaran dan kesediaan seseorang manaati semua peraturan perusahaan dan norma-norma sosial yang berlaku. Jadi kedisiplinan dapat diartikan bilamana karyawan datang dan pulang tepat waktunya, mengerjakan semua pekerjaan dengan baik, mematuhi semua peraturan perusahaan, dan norma-norma sosial yang berlaku. Kedisiplinan harus ditegakkan dalam suatu organisasi karena tanpa dukungan disiplin karyawan yang baik, 
maka sulit bagi organisasi untuk mengwujudkan tujuannya. Jadi kedisiplinan adalah kunci keberhasilan untuk mencapai tujuan.

Disiplin kerja adalah disiplin terhadap waktu kerja, dan disiplin dalam menaati peraturan yang telah ditetapkan dalam organisasi. Dengan adanya kesadaran yang tinggi dalam melaksanakan aturan-aturan organisasi yang diwujudkan dalam disiplin kerja yang tinggi, maka prestasi juga akan meningkat. Memelihara dan meningkatkan kedisiplinan yang baik adalah hal yang sulit, karena banyak faktor yang mempengaruhinya. Faktor-faktor tersebut antara lain : tujuan dan kemampuannya, teladan pimpinan, balas jasa (gaji dan kesejahteraan), keadilan, pengawasan melekat, sanksi hukum, ketegasan, peraturan, dan hubungan kemanusiaan. Jadi sangat jelas kontrol dari atasan merupakan salah satu faktor dalam menciptakan disiplin kerja karyawan. Selama perusahaan telah mempunyai peraturan dan aturan yang telah disepakati bersama, maka pelanggaran terhadap peraturan yang telah dibuat haruslah dikenakan tindakan pendisiplinan. Untuk menerapkan peraturan-peraturan tersebut diperlukan adanya peraturan disiplin yang memuat pokok-pokok kewajiban, larangan, dan sanksi apabila tidak ditaati larangan tersebut dilanggar.

Belum ada penelitian sebelumnya yang relevan dan ditulis dengan mencantumkan dari mana asal penelitian tersebut. Untuk mengiplementasikan kedisiplinan karyawan tidak cukup hanya dengan mempertajam pengenaan sanksi atau ancaman saja, tetapi perlu disertai dengan perbaikan tingkat kesejahteraan para karyawan, selain penegakan disiplin kerja untuk meningkatkan prestasi kerja karyawan dapat juga ditentukan oleh faktor-faktor lain. Jadi peranan kedisiplinan juga dalam hal ini sangat dibutuhkan. Pimpinan harus dapat memberikan contoh yang baik tentang disiplin kerja karyawannya, sehingga karyawan dapat menerapkan dalam pekerjaan mereka masing-masing. Dari uraian diatas jelas bahwa kedisiplinan itu sangat penting, fungsi kedisiplinan yang tepat digunankan untuk meningkatkan prestasi kerja karyawan. Maka dapat disimpulkan bahwa betapa pentingnya arti dari kedisiplinan dalam meningkatkan prestasi kerja karyawan, sebab itu sangat mempengaruhi karir seseorang kedepannya. Berdasarkan uraian tersebut, maka saya penulis tertarik dengan judul " Hubungan Antara Disiplin Kerja Dengan Kinerja Karyawan Pada Perusahaan PT. Mensa Bina Sukses Makassar “.

Berdasarkan latar belakang yang telah diuraikan diatas maka penulis merumuskan masalah : "Apakah terdapat hubungan antara tingkat disiplin kerja terhadap kinerja karyawan pada PT. Mensa Binsa Sukses Makassar.

Tujuan dan manfaat dari penelitian ini adalah :

\section{Tujuan Penelitian}

Adapun tujuan yang ingin dicapai dari penelitian ini adalah mengetahui hubungan tingkat disiplin kerja karyawan terhadap kinerja karyawan pada PT. Mensa Bina Sukses Makassar.

2. Manfaat Penelitian

Selanjutnya kegunaan yang ditargetkan dari penelitian ini adalah :

a. Bagi penulis

Mendapatkan pengalaman dalam penelitian terkait dalam bidang penelitian Manajemen Sumber Daya Manusia tentang kedisiplinan.

b. Bagi perusahaan

Dara hasil penelitian ini perusahaan dapat mengiplementasikan kepada kepada seluruh karyawannya terutama perusahaan PT. Mensa Bina Sukses Makassar

c. Bagi akademisi

penelitian ini berkontribusi bagi perkembangan para peneliti khususnya hubngan disiplin kerja terhadap kinerja karyawan

Setiap perusahaan pada umumnya menginginkan agar para karyawan yang bekerja dapat mematuhi tata tertib atau peraturan yang telah ditetapkan. Dengan adanya peraturan baik tertulis maupun tidak tertulis, diharapkan agar para karyawan dapat melaksanakan sikap dingin dalam bekerja sehingga produktivitasnya pun meningkat. Menurut wiryo (2001:291), disiplin kerja dapat didefinisikan sebagai suatu sikap menghormati, patuh, dan taat terhadap peraturanperatuan yang berlaku, baik yang tertulis maupun tidak tertulis serta sanggup menjalankannya 
dan tidak mengelak untuk menerima sanksi-sanksinya apabila ia melanggar tugas dan wewenang yang diberikan kepadanya. Menurut Mathis (2002:314),

Menurut Sadili (2010:22), manajemen sumber daya manusia (human resource manajemen)adalah sesuatu kegiatan pengelolaan yang meliputi pendayagunaan, pengembangan, penilaian balas jasa bagi menusia meliputi individu anggota organisasi atau perusahaan bisnis. Manajemen sumber daya manusia juga menyangkut cara-cara mendesain sistem perencanaan, penyusunan karyawan, pengelolaan karir, evaluasi kinerja, kompensasi karyawan, dan hubungan ketenaga kerjaan.

Menurut Hani Handoko (2001:6), manajemen sumber daya manusia merupakan suatu proses perencanaan, pengorganisasian, pengarahan, dan pengawasan kegiatan-kegiatan pengadaan, pengembangan, pemberian kompensasi, pengintegrasian, pemeliharaan, dan pelepasan sumber dayas manusia agar tercapai tujuan individu, organisasi dan masyarakat.

Sebagai landasan teoritis dalam menjabarkan penelitian ini, berikut beberap konsep yang terkait dengan obyek yang diangkat dalam penelitian mengenai analisis hubungan antara disiplin kerja dengan kinerja karyawan pada PT Mensa Bina Sukses Makassar.

Menurut Wibowo (2007:8) memandang manajemen kinerja sebagai proses komunikasi yang dilakukan secara terus-menerus dalam kemitraan antara karyawan dengan atasan langsung. Adapun kinerja sebagaimana yang dikemukaan oleh Mangkunegara (2006:13) menyatakan bahwa kinerja sumber daya manusia merupakan istilah dari kata job performance actual performance (prestasi kerja) adalah hasil kerja kualitas dan kuantitas yang dicapai oleh karyawan/pegawai dalam melaksanakan tugasnya sesuai dengan tanggung jawab yang diberikan kepadanya.

Berdasarkan rumusan masalah dan tugas peneliti diatas maka dapat dihipotesiskan "Terdapat pengaruh yang positif antara Tingkat Disiplin Kerja Terhadap Kinerja Karyawan Pada PT. Mensa Bina Sukses Makassar".

\section{METODE}

\subsection{Lokasi dan Waktu Penelitian}

Penelitian ini dilaksanakan pada PT. Mensa Bina Sukses Makassar yaitu perusahaan yang bergerak dibidang distributor obat-obatan dan alat kesehatan, atau yang biasa disebut farmasi yang berlokasi di jalan Ir. Sutami No. 19 Makassar, dan adapun waktu penelitian dilaksanakan selama 2 bulan yaitu awal bulan Februari sampai akhir Maret 2021.

\section{2. $\quad$ Metode Pengumpulan Data}

Metode penelitian lapangan yaitu mendapatkan data-data yang berhubungan langsung dengan penelitian, yaitu dengan cara mengadakan serangkaian kegiatan terhadap pengenalan obyek penelitian atau lokasi penelitian

a. Wawancara

Peneliti melakukan wawancara kepada para karyawan yang dapat memberikan informasi yang dibutuhkan.

b. Obeservasi

Pengamatan langsung setiap aktivitas kegiatan karyawan yang berhubungan dengan pekerjaan.

c. kuisioner

sebuah pernyataan tertulis yang digunakan utuk memperoleh informasi dari responden dalam arti laporan tentang pribadinya.

\subsection{Populasi dan Sampel}

Populasi penelitian ini adalah keseluruhan karyawan yang ada PT. Mensa Bina Sukses Makassar uang berjumlah 98 karyawan. Mengingat jumlah karyawan perusahaan PT. Mensa Bina Sukses relatif kecil $(\mathrm{n}<100)$ maka jumlah populasi yang ada sekaligus dijadikan sebagai sampel, sehingga jenis penelitian ini termasuk penelitian sensus. 


\subsection{Metode Analisis Data}

Analisis kuantitatif untuk mengetahui pengaruh disiplin kerja terhadap kinerja karyawan. Adapun metode regresi linier sederhana dengan formulasi sebagai berikut :

Persemaan regresi linier dari $\mathrm{Y}$ terhadap $\mathrm{X}$. Persamaan regresi linier dari $\mathrm{Y}$ terhadap $\mathrm{X}$ dirumuskan sebagai berikut :

$$
\mathrm{Y}=\mathrm{a}+\mathrm{bX}
$$

Dimana,

$$
\begin{array}{ll}
\text { Y } & : \text { Kinerja } \\
\mathrm{X} & : \text { Disiplin Kerja } \\
\mathrm{a} & : \text { Konstanta } \\
\mathrm{b} & : \text { Koefisien Variabel Bebas }
\end{array}
$$

$$
\begin{aligned}
b & =\frac{n \sum x y-\left(\sum x\right)\left(\sum y\right)}{\sqrt{n \sum n^{2}}-\left(\sum x\right)^{2}} \\
a & =\frac{\sum y}{n}-b \frac{\sum x}{n} \text { atau } a=y-b
\end{aligned}
$$

Untuk mengetahui kekuatan dan signifikansi hubungan antara dua variabel. Perhitungannya dapat dirumuskan sebagai berikut :

$$
r=\frac{n \sum x y-\left(\sum x\right)\left(\sum y\right)}{\sum x^{2}-\left(\sum x\right)^{2} \cdot n \sum y^{2}-\left(\sum y\right)^{2}}
$$

Dimana :

$\mathrm{r} \quad$ : Koefisien Kolerasi (besarnya 0 s.d \pm 1 )

$\mathrm{X}$ dan $\mathrm{Y} \quad$ : Variabel Penelitian

$\mathrm{Y} \quad$ : Kinerja

X : Disiplin Kerja

Menurut Usman (2008; 201), dan keseluruhan bobot data tersebut, maka dapat diklasifikasikan menjadi :

Selanjutnya perhitungan dilakukan dengan menggunakan perhitungan uji t, yakni untuk mencari pengaruh dari variabel yang ada, dimana langkah-langkah dalam menggunakan rumusnya adalah sebagai berikut :

a. buat formula hipotesis

- $\quad H_{0}: \mathrm{b}=0$ berarti tidak ada pengaruh antara variabel $\mathrm{X}$ dan $\mathrm{Y}$

- $\quad H_{i}: \mathrm{b}>0$ berarti ada pengaruh antara variabel $\mathrm{X}$ dan $\mathrm{Y}$

b. Menentukan nilai $t-$ tabel pada nilai alfa $(a)=0,05(n-k)$

c. Menentukan nilai t - hitung dengan rumus :

$$
t=\frac{\sqrt{n-2}}{\sqrt{1-(r)^{2}}}
$$

d. membandingkan hasil perhitungan antara $\mathrm{t}$ - tabel dengan $\mathrm{t}$ - hitung dimana apabila :
- $\mathrm{t}$ - hitung $\geq \mathrm{t}$ - tabel berarti
$H_{0}$ ditolak dan
$H_{i}$ diterima
- $\mathrm{t}-$ hitung $\leq \mathrm{t}-$ tabel berarti
$H_{0}$ ditolak dan
$H_{i}$ diterima 


\section{HASIL DAN PEMBAHASAN}

\subsection{Analisis Kedisiplinan Terhadap Kinerja Karyawan Pada PT. Mensa Bina Sukses Makassar}

Untuk mengetahui perngaruh displin kerja terhadap kinerja karyawan. Adapun metode regresi linear sederhana dengan formulasi. Persamaan regresi linier dari Y terhadap X. Persamaan regresi linier dari $\mathrm{Y}$ dan $\mathrm{X}$ dapat dirumuskan sebagai berikut :

$$
\mathrm{Y}=\mathrm{a}+\mathrm{bX}
$$

Dimana :

$\mathrm{Y}=$ Kinerja

$\mathrm{X}=$ Disiplin Kerja

$\mathrm{a}=$ Konstanta

$\mathrm{b}=$ Koefisien Variabel Bebas

$$
\begin{gathered}
b=\frac{n \sum x y-\left(\sum x\right)\left(\sum y\right)}{\sqrt{n} \sum n^{2}-\left(\sum x\right)^{2}} \\
a=\frac{\sum y}{n}-b \frac{\sum x}{n} \text { atau } a=y-b
\end{gathered}
$$

Selanjutnya akan disajikan tabulasi perhitungan antara disiplin karyawan terhadap kinerja melalui tabel berikut ini:

Untuk mengetahui kekuatan dan signifikansi hubungan antara dua variabel. Perhitungannya dapat dirumuskan sebagai berikut :

$$
r=\frac{n \sum x y-\left(\sum x\right)\left(\sum y\right)}{\sqrt{n} \sum x^{2}-\left(\sum x\right)^{2} \cdot n \sum y^{2}-\left(\sum y\right)^{2}}
$$

\section{Dimana :}

$\mathrm{r} \quad$ : Koefisien Korelasi (besarnya 0 s.d \pm 1)

$\mathrm{X}$ dan $\mathrm{Y}$ : Variabel Penelitian

$\mathrm{Y} \quad$ : Kinerja

$\mathrm{X} \quad$ : Disiplin Kerja

untuk mengetahui seberapa besar kedisiplinan terhadap kinerja karyawan, maka dapat dilihat melalui hasil perhitungan di bawah ini

$$
\begin{aligned}
& b=\frac{n \sum x y-\left(\sum x\right)\left(\sum y\right)}{n \sum x^{2}-\left(\sum x\right)^{2}} \\
& b=\frac{50(56923)-(1609)(1763)}{50(52005)-(1609)^{2}} \\
& b=\frac{(9483)}{(11369)}
\end{aligned}
$$

$$
\mathrm{b}=0,83
$$

Sedangkan nilai a dihitung sebagai berikut : 


$$
\begin{gathered}
a=\frac{\sum y}{n}-b \frac{\sum x}{n} \\
a=\frac{1763}{50}-(0,83) \frac{(1609)}{50} \\
a=8,55
\end{gathered}
$$

Dari perhitungan diatas persamaan regresi linear sederhana antara variabel $\mathrm{X}$ dan $\mathrm{Y}$ adalah :

$$
Y=8,55+083 X
$$

Selanjutnya dapat mengatakan bahwa jika setiap kedisiplinan kerja (X) bertambah sebesar 1 satuan, maka rata-rata $(Y)$ akan bertambah menjadi :

$$
\begin{aligned}
& Y=8,55+0,83(1) \\
& Y=8,55+0,83 \\
& Y=9,38
\end{aligned}
$$

Jadi kesimpulan dan dari persamaan regresi sederhana adalah koefisien regresi kedisiplinan karyawan terhadap kinerja adalah positif. Artinya ada pengaruh antara kedisiplinan karyawan terhadap kinerja dan pengaruhnya signifikan dan positif. Dimana nilai a (konstanta) sebesar 9,38 membawa arti bahwa setiap perubahan nilai b sebesar 0,83 membawa arti bahwa perubahan variabel independen $X$ (disiplin karyawan) sebesar 1 poin, maka akan diimbangi dengan perubahan variabel $Y$ (kinerja) sebesar 0,83 poin.

Jadi kesimpulan dari persamaan regresi sederhana adalah koefisien regresi disiplin kerja terhadap kinerja adalah positif. Artinya ada pengaruh antara disiplin kerja terhadap kinerja.

Dari hasil tabulasi perhitungan kuesioner untuk mencari keterkaitan antara disiplin kerja dan kinerja dapat dilihat dibawah ini :

$$
r=\frac{n \sum x y-\left(\sum x\right)\left(\sum y\right)}{n \sum x^{2}-\left(\sum x\right)^{2} \cdot n \sum y^{2}-\left(\sum y\right)^{2}}
$$

Dimana :

$$
\begin{array}{ll}
\mathrm{r} & : \text { Nilai Koefisien Korelasi } \\
\mathrm{n} & \text { : Sampel } \\
\mathrm{Y} & \text { : Kinerja } \\
\mathrm{X} & \text { : Displin Kerja }
\end{array}
$$

$$
r=\frac{n \sum x y-\left(\sum x\right)\left(\sum y\right)}{n \sum x y^{2}-\left(\sum x\right)^{2} \cdot n \sum y^{2}-\left(\sum y\right)^{2}}
$$

$r=0,86$

Koefisien korelasi (r) dinyatakan dalam persentase, sehingga makin mendekati satu (1) makin kuat ketergantungannya. Berdasarkan perhitungan diatas, hubungan antara disiplin kerja karyawan dengan kinerja karyawan adalah hubungan positif, yaitu 0,68 yang berada dalam kategori kuat

$$
\begin{array}{ll}
r^{2}= & (0,86)^{2} \\
r= & 0,4624 \%
\end{array}
$$


ini berarti bahwa hubungan disiplin kerja karyawan terhadap kepuasan kerja karyawan sebesar 0,4624 atau 46,24\%, sedangkan 53,76\% lainnya adalah dijelaskan oleh variabel lainnya. Dengan demikian hipotesis tersebut terbukti atau diterima.

\subsection{Pengujian Nilai Hubungan}

Untuk membuktikan hasil perhitungan hubungan antara disiplin kerja terhadap kinerja karyawan, maka perlu didakan pengujian terhadap koefisien tersebut apakah dapa diterima atau tidak dengan menggunakan uji t, rumusnya :

$t=\frac{\sqrt{n-2}}{\sqrt{1-(r)^{2}}}$

Langkah-langkah pengujian ini adalah

1. Ho ; $r=0$, tidak ada hubungan korelasi antara $X$ dan $Y$

Ho ; r $>0$, ada hubungan korelasi antara X dan $Y$

2. $\mathrm{a}=0,05$

3. daerah kritis dengan $\mathrm{a}=0,05$ dan derajat bebas $\mathrm{n}=2$

ta $=0,05(\mathrm{n}-2)$

$=0,05(50-2)$

$=2,4$ (tabel distribusi $\mathrm{t}$ )

4. perhitungan uji t

$$
\begin{aligned}
& t=\frac{\sqrt{n-2}}{\sqrt{1-(r)^{2}}} \\
& \mathrm{t}=8,73
\end{aligned}
$$

Dari pengujian koefisien korelasi diatas dapat dilihat bahwa t hitung $>$ tabel atau 8,73 > 2,4 maka Hi diterima dan Ho ditolak. Ini menyatakan bahwa tingkat kepercayaan 95\% dan a = 5\% maka benar ada hubungan yang signifikan antara kedisiplinan karyawan dengan kinerja. Dengan demikian kantor PT. Mensa Bina Sukses makassar hendaknya memperhatikan faktor yang sangat penting dalam mendukung peningkayan kinerja termasuk pemberian kedisiplinan pada karyawan. Dimana penelitian terdahulu dari penelitian Jatilaksono, S.R. (2016). Pengaruh Disiplin Kerja dan Budaya Organisasi terhadap Kinerja Karyawan CV. Abank Irenk Creative Yogyakarta. Skripsi. Program Studi Manajemen - Jurusan Manajemen Fakultas Ekonomi Universitas Negeri Yogyakarta. Dimana hasil penelitian terdapat pengaruh positif dan signifikan dengan taraf signifikansi antara disiplin kerja terhadap kinerja karyawan.

Tabel 1. Interpretasi Nilai $\mathrm{r}$

\begin{tabular}{cc}
\hline Nilai & Kriteria Hubungan \\
\hline $0,81-1,00$ & Sangat Tinggi \\
$0,61-0,80$ & Tinggi \\
$0,41-0,60$ & Sedang \\
$0,21-0,40$ & Kurang Tinggi \\
$0,01-0,20$ & Sangat Kurang \\
\hline
\end{tabular}

Sumber : Usman (2008;201) 


\section{A. Karakteristik Responden}

Tabel 2 Karakteristik Responden Berdasarkan Tingkat Usia

\begin{tabular}{cccc}
\hline NO & Usia & Jumlah (orang) & Persentase (\%) \\
\hline 1 & $<20$ & 8 & 16,00 \\
2 & $21-30$ & 24 & 48,00 \\
3 & $31-40$ & 12 & 24,00 \\
4 & $41-50$ & 6 & 12,00 \\
& Jumlah & 50 & 100 \\
\hline
\end{tabular}

Sumber : Data PT. Mensa Bina Sukses Makassar, 2021

Tabel 3 Karakteristik Responden Berdasarkan Tingkat Pendidikan

\begin{tabular}{cccc}
\hline NO & Pendidikan Terakhir & Jumlah (orang) & Persentase (\%) \\
\hline 1 & SMA & 30 & 60,00 \\
2 & Diploma & 6 & 12,00 \\
3 & S1 & 12 & 24,00 \\
4 & S2 & 2 & 4,00 \\
& Jumlah & 50 & 100 \\
\hline
\end{tabular}

Sumber : Data PT. Mensa Bina Sukses Makassar 2021

Tabel 4 Karakteristik Responden Berdasarkan Masa Kerja

\begin{tabular}{cccc}
\hline NO & Masa Kerja (Tahun) & Jumlah (orang) & Persentase (\%) \\
\hline 1 & $<5$ & 32 & 64,00 \\
2 & $6-10$ & 13 & 26,00 \\
3 & $11-20$ & 5 & 10,00 \\
& Jumlah & 50 & 100 \\
\hline
\end{tabular}

Sumber : Data PT. Mensa Bina Sukses, 2021

Adapun hasil kuisioner nantinya akan disajikan dalam tabel tabulasi persentase keeratan hubungan variabel dengan menggunakan perhitungan sebagai berikut :

Tabel 5 tabulasi hasil perhitungan kuesioner

\begin{tabular}{cccccc}
\hline Resp & X & Y & X2 & Y2 & XY \\
\hline 1 & 36 & 38 & 1296 & 1444 & 1368 \\
2 & 33 & 34 & 1089 & 1156 & 1122 \\
3 & 33 & 36 & 1089 & 1296 & 1188 \\
4 & 31 & 32 & 961 & 1024 & 992 \\
5 & 33 & 34 & 1089 & 1156 & 1122 \\
6 & 29 & 30 & 841 & 900 & 870 \\
7 & 36 & 40 & 1296 & 1600 & 1440 \\
8 & 33 & 38 & 1089 & 1444 & 1254 \\
9 & 34 & 36 & 1156 & 1296 & 1224 \\
10 & 31 & 39 & 961 & 1521 & 1209 \\
11 & 29 & 36 & 841 & 1296 & 1044 \\
12 & 34 & 38 & 1156 & 1444 & 1292 \\
13 & 32 & 36 & 1024 & 1296 & 1152 \\
14 & 35 & 40 & 1225 & 1600 & 1400 \\
15 & 32 & 37 & 1024 & 1369 & 1184 \\
16 & 31 & 38 & 961 & 1444 & 1178 \\
\hline
\end{tabular}




\begin{tabular}{|c|c|c|c|c|c|}
\hline Resp & $\mathbf{X}$ & $\mathbf{Y}$ & $\mathrm{X} 2$ & Y2 & $\mathrm{XY}$ \\
\hline 17 & 34 & 35 & 1156 & 1225 & 1190 \\
\hline 18 & 29 & 34 & 841 & 1156 & 980 \\
\hline 19 & 30 & 39 & 900 & 1521 & 1170 \\
\hline 20 & 35 & 36 & 1225 & 1296 & 1260 \\
\hline 21 & 31 & 31 & 861 & 961 & 961 \\
\hline 22 & 29 & 33 & 841 & 1089 & 957 \\
\hline 23 & 34 & 36 & 1156 & 1296 & 1224 \\
\hline 24 & 32 & 36 & 1024 & 1296 & 1152 \\
\hline 25 & 33 & 36 & 1089 & 1296 & 1188 \\
\hline 26 & 31 & 33 & 961 & 1089 & 1023 \\
\hline 27 & 33 & 38 & 1089 & 1444 & 1254 \\
\hline 28 & 29 & 32 & 841 & 1024 & 928 \\
\hline 29 & 36 & 40 & 1296 & 1600 & 1440 \\
\hline 30 & 34 & 36 & 1156 & 1296 & 1224 \\
\hline 31 & 32 & 34 & 1024 & 1156 & 1088 \\
\hline 32 & 35 & 36 & 1225 & 1296 & 1260 \\
\hline 33 & 32 & 34 & 1024 & 1156 & 1088 \\
\hline 34 & 33 & 35 & 1089 & 1225 & 1155 \\
\hline 35 & 29 & 32 & 841 & 1024 & 928 \\
\hline 36 & 36 & 40 & 1296 & 1600 & 1440 \\
\hline 37 & 33 & 35 & 1089 & 1225 & 1155 \\
\hline 38 & 34 & 38 & 1156 & 1444 & 1292 \\
\hline 39 & 31 & 35 & 961 & 1225 & 1085 \\
\hline 40 & 32 & 34 & 1024 & 1156 & 1088 \\
\hline 41 & 31 & 31 & 961 & 961 & 961 \\
\hline 42 & 32 & 36 & 1024 & 1296 & 1152 \\
\hline 43 & 29 & 31 & 841 & 961 & 899 \\
\hline 44 & 30 & 32 & 900 & 1024 & 960 \\
\hline 45 & 35 & 36 & 1225 & 1296 & 1260 \\
\hline 46 & 31 & 32 & 961 & 1024 & 992 \\
\hline 47 & 29 & 34 & 841 & 1156 & 986 \\
\hline 48 & 33 & 36 & 1089 & 1296 & 1188 \\
\hline 49 & 30 & 32 & 900 & 1024 & 960 \\
\hline 50 & 30 & 33 & 900 & 1089 & 990 \\
\hline$\Sigma$ & 1609 & 1763 & 52005 & 62509 & 56923 \\
\hline
\end{tabular}

\section{Sumber : Data diolah 2021}

\section{KESIMPULAN}

Setelah melakukan perhitungan dengan menggunakan metode dskriptif yakni mencari pengaruh kedisiplinan karyawan terhadap kinerja pada PT. Mensa Bina Sukses Makassar, maka dapat ditarik kesimpulan bahwa tingkat kedisiplinan karyawan memberikan hubungan yang positif dan signifikan hal ini ditujukkan dari hasil perhitungan, dimana nilai $r^{2}=(0,68)^{2}$ atau $\mathrm{r}=$ $0,4624 \%$ ini berarti bahwa hubungan disiplin kerja karyawan sebesar 0,4624 atau 46,24\%, sedangkan $53,76 \%$ lainnya adalah dijelaskan oleh variabel lainnya dengan demikian hipotesis tersebut terbukti atau diterima. 
Berdasarkan kesimpulan dari penelitian ini, maka saran-saran atau masukan bagi perusahaan dalam hal ini PT. Mensa Bina Sukses Makassar, Pimpinan PT. Mensa Bina Sukses Makassar, perlu mempertahankan bahkan meningkatkan program yang berhubungan kedisiplinan dengan menerapkan peraturan yang lebih keras kepada karyawannya dan Karena penelitian ini terbatas hanya dilingkungan PT. Mensa Bina Sukses Makassar, maka disarankan untuk peneliti-peneliti lain melakukan penelitian yang sejenis namun pada bidang usaha yang berbeda dan perusahaan yang berbeda.

\section{DAFTAR PUSTAKA}

Afandi, P. (2018). Manajemen Sumber Daya Manusia (Teori, Konsep dan Indikator). Riau: Zanafa Publishing.

Alwi, Safaruddin 2001. Manajemen Sumber Daya Manusia Keunggulan Kompetitif. Penerbit : BPFE, Yogyakarta.

Arishanti, K, I. (2006). Handout Psikologi Kelompok. Depok: Fakultas Psikologi Universitas Gunadarma.

Casimir, G., Waldman, D.A., Bartram, T., \& Yang. S. (2006). Trust and the Relationship Between Leadership and Follower Performance: Journal of Leadership \& Orgnizational Studies. 12 (3): 68-85.

Fazri., \& Tama, D.A. (2014). Hubungan Gaya Kepemimpinan Transformasional dan Gaya Kepemimpinan Transaksional dengan Disiplin Kerja pada Karyawan PT. Kembar Abadi Utama Di Kecamatan Batu Sopang Kabupaten Paser. eJournal Psikologi, 2014, 2 (2): 150161.

Gomes, Faustino. (2000). Manajemen Sumber Daya Manusia, Penerbit Andi Offset, Yogyakarta.

Handoko, T. Hani (2001), Manajemen Sumber daya Manusia. Penerbit BPFE, Yogyacarta.

Harsono, Wiryo. (2001). Manajemen Kinerja. Edisi ketiga. Penerbit BPFE, Yogyakarta.

Hasibuan, Malayu. (2001). Manajemen Sumber Daya Manusia. Bumi Aksara : Jakarta.

Jatilaksono, S.R. (2016). Pengaruh Disiplin Kerja dan Budaya Organisasi terhadap Kinerja Karyawan CV. Abank Irenk Creative Yogyakarta. Skripsi. Program Studi Manajemen Jurusan Manajemen Fakultas Ekonomi Universitas Negeri Yogyakarta.

Liyas, N.J. (2017). Pengaruh Kepemimpinan Terhadap Disiplin Kerja Karyawan pada PT. Bank Syariah Mandiri. JEBI (Jurnal Ekonomi dan Bisnis Islam)-Volume 2, Nomor 2, Juli-Desember 2017: 121-129.

Mathis. Robert L (2005). Manajemen Dan Evaluasi Kinerja. Lembaga. Penerbit Fakultas Ekonomi Univesitas Indonesia Jakarta.

Mangkunegara, A.A Anwar Prabu, (2006). Evaluasi Kinerja Sumber daya Manusia, Cetakan Keempat, Penerbit PT. Refika Aditama, Bandung.

Mangkuprawira, Tb. Syafri. (2003). Manajemen Sumber daya Manusia Strategik. Penerbit : Alfabeta Bandung.

Mathis. Robert L. dan Jackson, John H. (2002). Manajemen Sumber Daya Manusia Salemba Empat : Jakarta.

Meylani., Prastika \& Ibrahim, M. (2015). Pengaruh Disiplin Kerja Terhadap Kinerja Karyawan (Kasus Bagian Operasional PT. Indah Logistik Cargo Cabang Pekanbaru). Jom FISIP Vol. 2 No. 2 Oktober 2015: 1-11.

Nitisemito, Alex. S. (2000). Manajemen Personalia : Manajemen Sumber daya Manusia, Edisi Keempat, Ghalia Indonesia, Jakarta.

Notoatmojo (2003). Manajemen Sumber Daya Manusia. Penerbit : CV. Haji Masagung. Jakarta.

Rivai. Veithzhal. (2005), Manajemen Sumber daya Manusia Untuk Perusahaan. Penerbit, PT. Raja Grafindo Persada, Jakarta. 
Sadili, Samsuddin, (2010). Manajemen Sumber Daya Manusia. Cetakan Kedua, CV. Pustaka Setia Bandung.

Sastrihadiwiryo, Siswanto. (2001). Manajemen Tenaga Kerja Indonesia Pendekatan Administrasi dan operasional. Bumi Aksara, Jakarta.

Sedarmayanti. (2010). Manajemen Sumber Daya Manusia. Penerbit : Rafika Aditama.

Simamora, Henry. (2004), Manajemen Sumber Daya Manusia, Penerbit STIE YKPN, Yogyakarta.

Sugiono. (2002). Statistika untuk Penelitian. Bandung : Alfabeta.

Sulistiani. Ambar Teguh. (2003), Manajemen Sumber Daya Manusia (Edisi 2). Penerbit PT. Refika Aditama, Bandung.

Suyadi. Prawirosentono, (2005). Manajemen Sumber Daya Manusia Kebijakan Kinerja Karyawan. Penerbit : PT Raja Grafindo Persada. Jakarta.

Sutrisno, edy. (2009). Manajemen Sumber Daya Manusia. Penerbit Kencana. Jakarta.

Usman, Akbar. (2008). Pengantar Statistika. Penerbit : Bumi Aksara. Jakarta.

Wibowo, (2010). Manajemen Kinerja Cetakan K-3. PT Raja Grafindo Persada, Jakarta. 
